Nike Kocijančič Pokorn, Iva Jevtič, Jaka Čibej

\title{
"Nočem biti odvisna«: \\ Ali javne prevajalske in tolmaške storitve res negativno vplivajo na aktivno vključenost migrantov v državo gostiteljico?
}

\begin{abstract}
Ključne besede: prevajanje in tolmačenje za skupnost, prosilci za mednarodno zaščito, migracije, mobilnost, inkluzija, integracija, jezikovna politika, prevodni režim
\end{abstract}

DOI: $10.4312 /$ ars.10.2.47-62

\section{Uvod}

Pričujoči članek bo prikazal, kako se v določenih političnih okoljih govori o migracijah in kakšne posledice ima tak diskurz na konkretno obravnavo migrantov in njihovo oskrbo. Prispevek ponuja premislek o upravičenosti določenih političnih pozicij, ki omogočajo ali kratijo nudenje prevajalskih in tolmaških storitev migrantom $\mathrm{v}$ državi gostiteljici, ter poziva $\mathrm{k}$ premisleku in preoblikovanju obstoječih jezikovnih politik in ideologij, ki določajo, v kolikšni meri priseljencem pomagamo s to vrsto jezikovne podpore. $\mathrm{Z}$ raziskavo dejanske rabe različnih jezikovnih strategij prosilcev za mednarodno zaščito $\mathrm{v}$ Azilnem domu Vič v Ljubljani bomo poskušali odgovoriti na politične trditve, da nudenje prevajalske in tolmaške podpore onemogoča uspešno integracijo migrantov, ker naj bi ta podpora zmanjševala motivacijo migrantov za učenje jezika države gostiteljice. Raziskava je del projekta MIME, ${ }^{1}$ ki poskuša izoblikovati politično relevantne predloge ter določiti jezikovne politike in strategije, ki dosegajo kompromis med nasprotujočimi si težnjami po mobilnosti in inkluziji v večjezikovni Evropi (Grin in dr., 2015).

$\mathrm{V}$ prispevku bomo najprej določili temeljne koncepte in politični diskurz, ki prevajanje in tolmačenje vidi kot zapreko, ki zavira uspešno integracijo migrantov. Nadaljevali bomo s predstavitvijo metodologije raziskave v azilnem domu v Ljubljani ter opisali eksperimentalni del raziskave, ki mu bosta sledila predstavitev rezultatov kvantitativne in kvalitativne raziskave ter zaključek.

1 Raziskava, katere delne izsledke objavljamo v tem članku, je bila financirana s strani sedmega raziskovalnega okvirnega programa EU (FP7/2014-2018) v okviru interdisciplinarnega projekta št. 613344 (MIME - Mobilnost in inkluzivnost v večjezični Evropi (Mobility and Inclusion in Multilingual Europe)). 


\section{Definicije temeljnih poimov in prevodni režim $\checkmark$ Združenem kraljestvu}

$\mathrm{V}$ prevodoslovju $\mathrm{v}$ zadnjih dveh desetletjih opazimo vedno večje zanimanje za prevajanje in tolmačenje za skupnost (PTS): pregled znanstvenih člankov, ki so bili objavljeni na to tematiko od leta 1998 do 2012 (Vargas Urpi, 2012), kaže, da so se raziskovalci osredotočali na raznolike teme: od diskurzne analize in taksonomije diskurznih označevalcev $\mathrm{v}$ tolmačenem govoru, prek vrednotenja kvalitete prevajanja in tolmačenja, do določanja značilnosti prevajanja in tolmačenja v posebnih kontekstih (npr. na sodišču, v azilnem postopku, policijskih zaslišanjih, zdravstveni oskrbi, izobraževanju in v postopkih centrov za socialno delo). Sodobnejši prispevki na tem področju se posvečajo tehnološkim pripomočkom za prevajanje in tolmačenje za potrebe skupnosti, specifični terminologiji in glosarjem, ki so izdelani za te namene, zgodovini PTS, specifičnim kompetencam, ki jih potrebujejo prevajalci in tolmači na tem področju, izobraževanju prevajalcev in tolmačev za PTS, deontološkim in etičnim problemom PTS ter pogojem dela in profesionalizaciji PTS. Ta povečan interes je gotovo posledica dejstva, da se $\mathrm{v}$ zadnjih letih številne države, ki prej niso imele izkušnje $\mathrm{z}$ migranti, soočajo $\mathrm{z}$ vedno številčnejšo večjezično migracijo, ki povzroča tudi številne družbene probleme. $V$ tem članku se bomo uvrstili med tiste raziskave, ki ugotavljajo, v kolikšni meri določena jezikovna politika vpliva na prevodni režim določene države (npr. Ozolins, 2010), tj. na določeno prevodno teritorialno politiko, ki jo oblasti uporabljajo za komunikacijo s svojim večjezikovnim prebivalstvom (Meylaerts, 2011a) ter na ta način spodbujajo ali ovirajo inkluzijo priseljencev in mobilnost prebivalcev.

$\mathrm{Z}$ uporabo pojma »mobilnost« želimo označiti realnost, ki je kompleksnejša od tega, kar ponavadi označujemo s pojmom »migracije«, in sicer želimo zajeti premike ljudi, ki izhajajo iz več kot ene države in so namenjeni v več kot eno ciljno državo, ki $\mathrm{v}$ različnih okoljih ostajajo različno dolgo, ki lahko vzdržujejo (še posebej s pomočjo tehnologije) neposreden stik $\mathrm{z}$ okoljem, iz katerega izhajajo, in zato zanje prehod $\mathrm{v}$ novo jezikovno okolje ni tako radikalen in je reverzibilen (Grin in dr., 2014, 9). S pojmom »inkluzija " pa zaznamujemo sprejemanje ali pripadnost različnim skupinam, in sicer od tradicionalnih skupin, ki se lahko izkažejo z državljanstvom, do skupin, ki so bolj prehodnega značaja in so vezane zgolj na kraj bivanja ali na določeno dejavnost (npr. delo, študij), in sicer tako, da so ustvarjeni pogoji, ki vsem članom skupnosti omogočajo dostop do vseh pomembnih vidikov družbenega udejstvovanja: na primer, da jim je omogočen dostop do socialnega varstva in političnega udejstvovanja, kvalitetnega izobraževanja, primarnega zdravstvenega varstva, enakopravnega sodelovanja $\mathrm{v}$ sodnih postopkih itd. V govoru političnih struktur se izraz inkluzija pogosto zamenjuje $\mathrm{z}$ izrazom integracija. 
Pojem »jezikovna politika« bo tu uporabljen v pomenu »jezikovnega teritorialnega režima«, tj. skupka zakonskih določb, ki urejajo rabo jezika v izobraževalnem sistemu in javni komunikaciji v pravnem in političnem okolju ter določajo rabo jezika v medijih in administraciji (Meylaerts, 2011b, 745). Del vsake jezikovne politike je prevodna politika, saj uravnavanje rabe jezika v družbi nujno vodi do določitve, kdo ima pravico do prevodnih in tolmaških storitev v družbi. Te določitve se odražajo tudi v zakonskih določbah, ki lahko odrejajo prevodno in tolmaško podporo v izobraževanju, sodnem sistemu, političnih institucijah, medijih in administraciji. Preprosteje povedano: država izoblikuje jezikovni in prevodni režim, ki določa, katere jezike se lahko oz. se mora uporabljati in prevajati ali tolmačiti $\mathrm{v}$ določenem prostoru in $\mathrm{v}$ določenih institucionalnih okvirih.

Jezikovne politike posameznih držav nihajo med zasledovanjem ideala zagotavljanja popolne večjezikovnosti in popolne enojezikovnosti. Prva možnost v čisti obliki ni vzpostavljena $\mathrm{v}$ nobeni državi, ker bi zagotavljanje popolne institucionalne večjezikovnosti $\mathrm{z}$ obvezo prevajanja in tolmačenja za vse jezike za vse prebivalce predstavljalo preveliko finančno breme za državo (prim. Ertl, Pöllabauer, 2010). Na drugi strani pa tudi ne najdemo popolnoma monolingvalnih držav, saj so tudi tiste države, ki se načeloma odločajo za vzpostavitev enojezikovnosti v državnem okviru (na primer Francija, Japonska ipd.), primorane vzpostaviti sistem jezikovne podpore priseljencem, kadar ti stopajo v stik s sodstvom, državno administracijo ali javnim zdravstvenim sistemom (Meylaerts, 2011b, 749-750).

Vsaka jezikovna in prevodna politika posamezne države, ki se načeloma odloča za demokratične procese odločanja, se ob migracijah sooča s problemom, kako se odzvati na prisotnost tujejezičnih prebivalcev in jim omogočiti inkluzijo v družbo. Vključevanje tujejezičnih prebivalcev namreč predstavlja breme za javne finance, saj $\mathrm{v}$ določenih kontekstih neizogibno poveča stroške za prevodne in tolmaške storitve. Dejanski izračuni stroškov za te storitve nam niso znani: še najbolj natančno jih beležijo v Združenem kraljestvu, kjer so mediji poročali, da so stroški za prevajanje in tolmačenje $v$ javnem sektorju leta 2005 znašali 100 milijonov funtov (Easton, 2006), leta 2008 so narasli na 110 milijonov funtov (Schäffner, 2009, 169), leta 2013 pa so znašali 140 milijonov funtov (Iredale, 2014). V teh letih je britanska politika preoblikovala jezikovni in prevodni režim ter se začela zavzemati za omejevanje prevajalskih in tolmaških storitev, namenjenih priseljencem, zato ni presenetljivo, da zadnji podatki kažejo na znižanje stroškov, in sicer naj bi leta $2014 \mathrm{v}$ Združenem kraljestvu za te storitve porabili »le« 100 milijonov funtov (Beckford, Adams, 2015).

Ne samo zaradi razmeroma visokih stroškov, namenjenih prevajanju in tolmačenju, državne uprave (še v večji meri pa mediji in javno mnenje) vedno pogosteje podpirajo 
ukrepe, ki ukinjajo ali omejujejo prevodno in tolmaško pomoč priseljencem, in sicer zaradi mnenja, da večjezičnost in večkulturnost, ki ju prevajanje in tolmačenje po njihovem mnenju ohranjata, ne spodbujata, temveč celo ovirata priseljence pri tem, da bi se naučili in uporabljali jezik države gostiteljice. To stališče opaža Schuck v Združenih državah Amerike (Schuck, 2009, 162, 170), Schäffner pa v Združenem kraljestvu. Schäffner v svoji natančni analizi novinarskega diskurza o prevajanju v Združenem kraljestvu leta 2009 ugotavlja, da se s poudarjanjem visokih stroškov za prevajalske in tolmaške storitve ter izpostavljanjem primerov priseljencev, ki ne znajo angleško, javno mnenje in uradna politika konsolidirata $\mathrm{v}$ podpori enojezične jezikovne politike. Tako je, na primer, leta 2007 laburistična britanska ministrica za skupnosti in državno upravo Ruth Kelly zapisala, da nudenje prevajalskih in tolmaških storitev zmanjšuje potrebo migrantov po učenju angleščine in s tem ovira proces integracije (glej Schäffner, 2009, 101). To stališče so povzeli številni mediji in ga podprli tudi z izjavami priseljencev. BBC-jev novinar Mark Easton (2006) tako poroča, da je neka poljska gradbena inženirka Agneska, ki v Britaniji živi že tri leta in še vedno ne zna angleško, sedaj povrh vsega še nezaposlena in prosi za podporo, za kar pa potrebuje tolmača. Ko jo novinar vpraša, ali bi se naučila angleško, če ne bi imela na voljo tolmača, Agneska odgovori: »Absolutely, yes.« (»Seveda, da.«) Podobno stališče zavzamejo tudi bangladeški sogovorniki. Novinar navaja izjavo neke bangladeške ženske, da so prevajalske in tolmaške podpore škodljive: »Ko nam poskušate pomagati, nam v resnici škodujete. « ${ }^{2}$ Neka druga ženska še pristavi, da bi moral obstajati zakon, ki bi zahteval obvezno učenje angleščine, saj mnogi možje ženskam ne dovolijo, da bi nemoteno komunicirale $\mathrm{z}$ okolico. Prevajanje in tolmačenje tako v tem diskurzu postaneta celo podpora zasužnjevanju žensk (ibid.).

Ta negativni odnos do prevajanja in tolmačenja ni strankarsko specifičen, saj je preživel tudi zamenjavo vlade: v konzervativno-liberalni vladi je zelo podobno stališče do prevoda zavzel Eric Pickles, minister za skupnosti in državno upravo. Ta je leta 2013 v pisnem sporočilu britanskemu parlamentu zapisal, da "prevajalske storitve nenačrtno, a škodljivo vplivajo na integracijo, saj v nekaterih migrantskih skupnostih zmanjšujejo potrebo po učenju angleščine«. To stališče je ohranil do konca svojega mandata. Leta 2015 so časopisi poročali, da je zaradi večjih izdatkov za prevod izjavil naslednje: »Navodila, ki sem jih dal, so bila kristalno jasna - občine denarja davkoplačevalcev ne smejo več trošiti za prevode v tuje jezike. Prevod ljudem onemogoča, da bi se integrirali v britansko družbo. Če ne znajo govoriti angleško, ne morejo uspeti v življenju. To samo pokaže, kako politična korektnost naredi več škode kot koristi «³ (Beardmore, 2015; Beckford, Adams, 2015).

2 "'When you are trying to help us, you are actually harming us, " she says."

3 "The guidance I've issued is crystal-clear - councils should stop wasting taxpayers' money by translating into foreign languages. Translation holds people back from integrating into British society. 
Čeprav se je prevodoslovna skupnost na trditve o »škodljivosti prevoda" zgodaj načelno odzvala (prim. Schäffner, 2008, 2009; Pym, 2014) in opozorila na neutemeljena stališča, ki so nekritično podpirala dominantno enojezično jezikovno politiko, zanemarila večjezikovno stvarnost sodobne britanske družbe in se na koncu še materializirala v političnih usmeritvah, ni podala nobenih dejanskih in preverljivih podatkov, s katerimi bi jih lahko dokončno zavrnila. Christina Schäffner je tako prevodoslovno skupnost pozvala, naj izvede »obsežne raziskave dejanskih situacij, $\mathrm{v}$ katerih priseljenci komunicirajo brez ali pa s pomočjo prevajalcev in tolmačev« (2009, 119). Raziskava, opisana v tem članku, odgovarja na ta poziv in poskuša odgovoriti na vprašanje, ali nudenje prevajalskih in tolmaških storitev res zmanjšuje potrebo migrantov po učenju jezika države gostiteljice.

\section{Metodologija in izbira vzorca}

Podatke za raziskavo smo zbirali na podlagi intervjujev s stanovalci ${ }^{4}$ iz azilnega doma $\mathrm{v}$ Ljubljani, ki prosilcem za mednarodno zaščito nudi nastanitev, brezplačne tolmaške in prevajalske storitve $\mathrm{v}$ času izvajanja postopka za pridobitev azila ter različne dejavnosti, kot so tečaji slovenščine, športne dejavnosti in ustvarjalne delavnice. Prosilci za mednarodno zaščito so bili izbrani zato, ker je to edina skupina priseljencev, ki jim država zagotavlja strokovno tolmaško podporo, kar pomeni, da imajo vsi izkušnjo $s$ tolmačenim sporazumevanjem, obenem pa je to tudi edina skupina priseljencev, ki jim država zastonj omogoča obiskovanje tečaja slovenščine. Pravico do udeležbe v brezplačnem tečaju slovenskega jezika in kulture ureja 103. člen, tolmačenje postopka za mednarodno zaščito pa 6. člen Zakona o mednarodni $z a s ̌ c ̌ i t i ~(2016)$, ki določa, kdo lahko tolmači v azilnem postopku (zahtevajo potrdilo o znanju jezika, izjavo o nesodelovanju $\mathrm{z}$ oblastmi države, katere jezik je tolmačen, ter dokaze o nekaznovanosti oz. neudeleženosti v kazenskem postopku), in zagotavlja, da so stroški za tolmačenje pokriti iz sredstev ministrstva za notranje zadeve.

Azilni dom lahko sprejme približno 200 prosilcev, v drugi polovici leta 2014, ko smo opravili večino intervjujev, pa je bilo v njem nastanjenih skupno 65 oseb. 9 oseb je bilo mladoletnih in jih zato v raziskavo nismo vključili, preostalih 56 oseb pa je prihajalo iz vzhodne Evrope (29 \%), Afrike (22 \%), z Bližnjega vzhoda (20 \%), bivše Jugoslavije (18 \%), Azije ( $9 \%$ ) in Južne Amerike (2 \%). Na podlagi podatkov o geografski sestavi populacije smo izoblikovali vzorec in posneli skupno 21 intervjujev z 19 prosilci za azil iz vseh štirih najbolj zastopanih regij v takratni populaciji: 3 iz

If they can't speak English, they're not going to get on in life. This shows how political correctness does more harm than good."

$4 \quad$ V članku je uporabljena moška oblika, ki velja za oba spola. 
Afrike (Nigerija, Kamerun in Alžirija), 3 iz bivše Jugoslavije (Kosovo ter Bosna in Hercegovina), 10 z Bližnjega vzhoda (Sirija, Irak, Iran in Afganistan) in 3 iz vzhodne Evrope (Ukrajina). Na ta način smo zajeli vsa največja krizna območja. Z dvema prosilcema $^{5}$ nam je leta 2015 uspelo opraviti tudi ponovitveni intervju, s katerim smo želeli preveriti, ali je v času njunega bivanja prišlo do morebitnih sprememb v rabi komunikacijskih strategij.

\section{Rezultati raziskave}

Intervjuji so večinoma potekali $\mathrm{v}$ angleščini (štirje $\mathrm{v}$ slovenščini, dva $\mathrm{v}$ srbohrvaščini in eden $\mathrm{v}$ francoščini ob pomoči tolmačke), trajali pa so približno 15-25 minut. Vsebovali so 48 vprašanj, sestavljeni pa so bili iz kvantitativnega in kvalitativnega dela.

Vsi intervjuvanci so bili pred intervjujem seznanjeni $\mathrm{z}$ namenom raziskave in so podpisali soglasje za znanstveno uporabo posnetih intervjujev. Intervjuje smo nato transkribirali, anonimizirali in analizirali, najpomembnejše rezultate pa predstavljamo v nadaljevanju.

\section{1 Kvantitativni del}

Pri kvantitativnem delu so intervjuvanci s pomočjo izpraševalca izpolnili vprašalnik, s katerim smo zbrali nekatere demografske podatke: spol in starost intervjuvanca, dosežena stopnja izobrazbe in število let šolanja, država bivanja med tretjim in desetim letom starosti, država bivanja dve leti pred prihodom v Slovenijo, znanje jezikov ter raba jezikov $\mathrm{v}$ različnih situacijah in $\mathrm{z}$ različnimi sogovorniki (npr. katere jezike govorijo s starši, s partnerjem, $\mathrm{z}$ otroki ipd.).

Med 19 intervjuvanci je bilo 11 moških in 8 žensk, starih od 19 do 55 let, a je bila večina intervjuvancev v svojih dvajsetih ali tridesetih letih: povprečna starost je bila 30 let, mediana 27 let, standardni odklon pa 8 let.

Po izobrazbeni strukturi so 3 intervjuvanci (16\%; iz Kameruna, Nigerije in Afganistana) dosegli osnovnošolsko izobrazbo, 7 pa jih je doseglo srednješolsko (39 \%) in 9 visokošolsko oz. univerzitetno ( 45 \%; 5 z Bližnjega vzhoda in 2 iz Ukrajine). Šolali so se od 5 do 17 let, v povprečju pa 11,5 leta (mediana je 12 let, standardni odklon pa 4 leta).

Kot jezik, ki ga najlažje uporabljajo, so intervjuvanci navedli arabščino (6 intervjuvancev), ruščino (3 intervjuvanci), kurdijščino (2 intervjuvanca), albanščino

5 Velike večine intervjuvancev eno leto po prvem intervjuju ni bilo več v azilnem domu. 
(2 intervjuvanca), dari (2 intervjuvanca) ter bosanščino, francoščino, ibo in perzijščino (po 1 intervjuvanec).

Do izvedbe intervjuja so intervjuvanci v Sloveniji bivali v povprečju 8,5 meseca: najmanj 1 teden, največ pa 5 let. Poudariti je treba, da jih je bila polovica v Sloveniji manj kot dva meseca. Mediana je 2 meseca, standardni odklon pa 15 mesecev, in sicer zaradi treh intervjuvancev, ki so tu že dalj časa: 20 mesecev (Afganistan M19), 3 leta (Ukrajina Ž42) in 5 let (Afganistan M22).

Podatki kažejo, da je vzorec precej uravnotežen po spolu, po starosti pa zajema predvsem mlajšo generacijo $\mathrm{v}$ dvajsetih in tridesetih letih, ki je povečini dosegla srednješolsko ali univerzitetno izobrazbo. Tudi $\mathrm{z}$ vidika jezikovne strukture je vzorec $\mathrm{z}$ 9 različnimi jeziki precej raznoroden.

\subsection{Kvalitativna analiza}

Kvalitativni del intervjuja je bil sestavljen iz odprtih vprašanj, ki so zadevala predvsem intervjuvančev odnos do jezikov (npr. ali obstaja jezik, ki se ga ne bi želel učiti, četudi bi bile učne ure brezplačne; ali obstaja jezik, ki ga sicer govori, a nerad uporablja) ter načine, s katerimi razrešuje komunikacijske težave, ko naleti na sogovornika, s katerim se ne more sporazumevati v svojem maternem jeziku. Pri načinih razreševanja komunikacijskih težav smo se osredotočali na pet glavnih strategij: rabo lingue france (npr. angleščine, francoščine ali srbohrvaščine), pomoč prevajalca ali tolmača (bodisi uradnega bodisi neuradnega), medrazumevanje, tj. sporazumevanje, kjer vsak izmed sogovornikov uporablja svoj jezik, jezika pa sta si ponavadi sorodna (npr. ruščina in slovenščina), rabo spletnih orodij za strojno prevajanje (npr. Google Prevajalnik) ali spletnih slovarjev ter rabo slovenščine, tj. dominantnega jezika države gostiteljice. Intervjuvanci so pri vsaki od navedenih strategij na lestvici od 1 (nikoli) do 5 (vedno) ocenili, kako pogosto jo uporabljajo, in po možnosti navedli konkretne situacije, v katerih so komunikacijske težave razrešili $z$ uporabo določene strategije. Posebno pozornost smo namenili vlogi prevajalskih in tolmaških storitev v njihovem življenju, intervjuvanci pa so odgovorili tudi na nekaj vprašanj v zvezi z učenjem slovenščine (npr. ali so že obiskovali brezplačne tečaje slovenščine v azilnem domu oziroma, če niso, ali bi si to želeli).

Intervjuje smo razdelili v dve skupini: v prvo smo uvrstili tiste, ki so nastali, ko so bili intervjuvanci v Sloveniji od nekaj tednov do 7 mesecev, v drugo pa tiste, ki so nastali z intervjuvanci, ki so v Sloveniji bivali več kot 7 mesecev, in dva ponovna intervjuja, kar pomeni, da prvo skupino sestavlja 15, drugo pa 5 intervjujev.

Zaradi prostorskih omejitev se bomo v tem prispevku osredotočili zgolj na nekaj vprašanj, ki se neposredno vežejo na motivacijo učenja jezika države gostiteljice. 


\subsubsection{Intervjuji z osebami, ki so v državi gostiteljici 7 mesecev ali mani}

V to skupino se je uvrstilo 15 intervjuvancev. V Tabeli 1 so prikazani odgovori na naslednja vprašanja:

a) Ali se vam zdi pomembno znati jezik države, v kateri živite?

b) Ali ste od prihoda $v$ Slovenijo obiskovali brezplačni tečaj slovenščine?

c) Ali bi želeli obiskovati brezplačni tečaj slovenščine?

Drugo vprašanje je bilo zastavljeno, ker so tečaji slovenščine v azilnem domu organizirani ciklično, kar pomeni, da se nekateri prosilci ne morejo takoj vključiti v tečaj in morajo počakati, da se potekajoči tečaj izteče in začne nov cikel.

Tabela 1: Intervjuji z osebami, ki so v Sloveniji 7 mesecev ali manj.

\begin{tabular}{|c|c|c|c|c|c|}
\hline Šifra & Izobrazba & $\begin{array}{l}\text { Čas bivanja } \\
\text { v Sloveniji } \\
\text { (v mesecih) }\end{array}$ & $\begin{array}{c}\text { Ali je znanje jezika } \\
\text { države gostiteljice } \\
\text { pomembno? }\end{array}$ & $\begin{array}{c}\text { Ali ste se } \\
\text { udeležili tečaja } \\
\text { slovenščine? }\end{array}$ & $\begin{array}{c}\text { Ali bi se želeli } \\
\text { udeležiti tečaja } \\
\text { slovenščine? }\end{array}$ \\
\hline Alžirija M23 & S & 3 & $\mathrm{NE}$ & DA & $\mathrm{NE}$ \\
\hline Bosna Ž27 & $S$ & 4 & $\mathrm{DA}$ & $\mathrm{NE}$ & $\mathrm{DA}$ \\
\hline Kamerun Ž28 & $\mathrm{O}$ & 1 & $\mathrm{DA}$ & $\mathrm{NE}$ & $\mathrm{DA}$ \\
\hline Irak M35 & S & 1 & $\mathrm{DA}$ & $\mathrm{NE}$ & $\mathrm{DA}$ \\
\hline Kosovo M34 & $\mathrm{S}$ & 3 & DA & DA & DA \\
\hline Nigerija Ž28 & $\mathrm{O}$ & 7 & $\mathrm{DA}$ & $\mathrm{DA}$ & $\mathrm{DA}$ \\
\hline Sirija Ž27 & $\mathrm{U}$ & 2 & $\mathrm{DA}$ & $\mathrm{NE}$ & $\mathrm{DA}$ \\
\hline Sirija M55 & S & 2 & $\mathrm{DA}$ & $\mathrm{NE}$ & $\mathrm{DA}$ \\
\hline Ukrajina M23 & $\mathrm{U}$ & 7 & $\mathrm{DA}$ & $\mathrm{DA}$ & $\mathrm{DA}$ \\
\hline Iran M30 & $\mathrm{U}$ & 2 & $\mathrm{DA}$ & $\mathrm{NE}$ & $\mathrm{DA}$ \\
\hline Irak Ž23 & $\mathrm{U}$ & 0,25 & DA & $\mathrm{NE}$ & DA \\
\hline Irak M27 & $\mathrm{U}$ & 0,5 & $\mathrm{DA}$ & $\mathrm{DA}$ & DA \\
\hline Kosovo M33 & $\mathrm{U}$ & 0,5 & $\mathrm{DA}$ & $\mathrm{NE}$ & $\mathrm{DA}$ \\
\hline Sirija Ž26 & $\mathrm{U}$ & 1 & $\mathrm{DA}$ & $\mathrm{NE}$ & $\mathrm{DA}$ \\
\hline Sirija M33 & S & 1 & DA & NE & DA \\
\hline
\end{tabular}

$\mathrm{O}$ - osnovnošolska, S - srednješolska, U - univerzitetna.

Na vprašanje, ali se jim zdi pomembno znati jezik države, v kateri živijo, je skupno 14 intervjuvancev odgovorilo pritrdilno. Izjema je bil Alžirija M23, ki je menil, da je dovolj že znanje angleščine, ki jo je opredelil kot mednarodni jezik, ki ga govorijo povsod. Kljub temu mnenju se je udeležil tečaja, ker mu je ta razbil monotonost bivanja v azilnem domu. Ostalih 14 intervjuvancev je svoj odgovor utemeljilo na 
različne načine, ki pa jih je mogoče strnjeno povzeti v željo po sporazumevanju in stiku z ljudmi. Izpostavili so na primer, da se zlasti s starejšimi ljudmi ne morejo pogovarjati $\mathrm{v}$ angleščini, $s$ tega vidika pa so poudarili tudi razliko med urbanim in ruralnim okoljem. Irak M27 pravi: ${ }^{6}$

»Velikokrat sem šel ven in spraševal starejše ljudi, a niso znali angleško. Mislim, da samo mlajše generacije govorijo angleško. Zato se je bolje naučiti slovensko. $\ll^{7}$

Obenem izpostavi, da se odnos ljudi spremeni, če govorimo njihov jezik:

»Vsakič, ko grem ven, me ljudje gledajo takole.

Kaj to pomeni, takole?

Kot neznanca, kot tujca. Če govoriš slovensko, je boljše. Ljudje mislijo, da si od tu, in si mislijo ... Ne vem ... Ne morem pojasniti. Vsakič, ko grem ven, vzamem nahrbtnik. Boljše je, če mislijo, da sem turist, in me ne gledajo takole. $\aleph^{8}$

Zavedajo se tudi, da je znanje slovenščine zelo pomembno pri iskanju zaposlitve in medosebnih odnosih. Izpostaviti je vredno tudi njihovo željo po neodvisnosti, saj je po njihovem mnenju mnogo lažje in bolj praktično znati jezik ter se v vsakdanjem življenju (v trgovini, pri zdravniku ipd.) sporazumevati sam. Ukrajina Ž26 pravi:

»Ali se vam zdi pomembno govoriti jezik dežele, v kateri živite?

Ja.

Zakaj pa?

Zakaj ... Ker je pomembno. Zato ker ... To je zame bolj udobno.

Na kakšen način?

Potem si bolj ... independent. Samostojen, neodvisen."

Intervjuvance smo tudi vprašali, ali so od prihoda $\mathrm{v}$ azilni dom že obiskovali brezplačni tečaj slovenščine. 5 jih je tečaj že obiskovalo - od teh je en intervjuvanec (Kosovo M34) tečaj nehal obiskovati, ker se mu ni zdel dovolj zanimiv, eden (Irak M27) pa je izpostavil, da ga obiskuje, a se mu zdi bolj učinkovito, če se uči sam (npr. z gledanjem televizijskih oddaj s slovenskimi podnapisi):

6 Z nezaznamovano pisavo je naveden govor intervjuvanca, $z$ ležečo pa govor izpraševalca. Simbol »...« zaznamuje premolk govorca. Citati so podani v slovenščini, v opombi pa je dodan izvirnik, če je intervju potekal v drugem jeziku.

7 »I went out many times and I asked older people and they couldn't speak English. So I think only the younger generations speak English. So it's better to learn Slovenian.«

8 "Every time I go out, people look at me like this.

What does that mean, like this?

As a stranger, a foreigner. If you speak Slovene, it's better. People think that you're from here, and they think about you ... I don't know ... I can't explain it. Everytime I go out, I take my backpack. It's better if they think I'm a tourist and don't look at me like this." 
»Brezplačni tečaj? Osnovni tečaj? Ja, rad bi šel, a ne maram tečajev in takih stvari, rad bi se učil sam. To je zame lažje. [...] Ne, na primer, sinoči sem gledal film v angleščini, ki je bil preveden v slovenščino. Nekdo v filmu je rekel 'thanks' in 'hvala'. «"

Preostalih 10 tečaja še ni obiskovalo, a so vsi izrazili željo, da bi to radi storili čim prej. Poudariti je treba, da je teh 10 intervjuvancev v azilnem domu stanovalo v povprečju le 1,5 meseca (od 1 tedna do 7 mesecev, polovica mesec dni ali manj). Intervjuvanka Bosna Ž27, ki je bila v azilnem domu 4 mesece, je povedala, da bi tečaj že začela obiskovati, a ima otroke in je tečaj zanjo časovno neugoden. Tečaj je obiskoval tudi intervjuvanec Alžirija M23, ki je menil, da slovenščine ne potrebuje, ker zadošča že znanje angleščine - tečaja pa se je udeležil kot dodatne dejavnosti, s katero je zapolnil svoj prosti čas.

\subsubsection{Intervjuji z osebami, ki so $v$ državi gostiteljici več kot 7 mesecev}

S to skupino smo intervjuje opravili, ker smo želeli izvedeti, ali se odnos do dominantnega jezika države gostiteljice spremeni $\mathrm{z}$ daljšim časom bivanja. Dva intervjuvanca smo ponovno intervjuvali po nekajmesečnem premoru, $z$ ostalimi prvotnimi intervjuvanci pa ponovnih razgovorov žal nismo mogli opraviti, saj jih ni bilo več v azilnem domu: nekateri so dobili negativno odločbo in so morali zapustiti državo, drugi pa so odšli sami in se je za njimi izgubila sled. Iz tega vzroka smo opravili dva dodatna intervjuja s prosilcema za mednarodno zaščito, ki sta prvotno bivala $\mathrm{v}$ azilnem domu, nato pa izkoristila možnost bivanja izven doma. Ta skupina intervjuvancev je predstavljena $\mathrm{v}$ Tabeli 2 .

Tabela 2: Intervjuji z osebami, ki so v Sloveniji več kot 7 mesecev.

\begin{tabular}{lll}
\hline \multicolumn{1}{c}{ Šifra } & Izobrazba & Čas bivanja v Sloveniji v času intervjuja v mesecih \\
\hline Afganistan M19 & $\mathrm{O}$ & 20 \\
\hline Ukrajina M23 P & $\mathrm{U}$ & 10 \\
\hline Iran M30 P & $\mathrm{U}$ & $4,5^{*}$ \\
\hline Ukrajina Ž42 & $\mathrm{S}$ & 36 \\
\hline Ukrajina Ž26 & $\mathrm{U}$ & 10 \\
\hline Afganistan M22 & $\mathrm{U}$ (študent) & 60
\end{tabular}

* CCeprav je bil intervjuvanec Iran M30 v času drugega intervjuja v Sloveniji manj kot 7 mesecev, smo se odločili, da ga kot ponovitveni intervju vključimo v drugo skupino, skupaj z intervjuvanci, ki so tu dalj časa.

9 »Free lessons? Basic lessons? Yeah, I would like, but I don't like classes and stuff like that, I want to learn by myself. It's easier for me. [...] No, for example, last night I was watching a TV movie in English, translated to Slovene. Someone in the movie said thanks, and 'hvala'." 
Iz teh intervjujev bomo predstavili odgovore na naslednje vprašanje: »Če bi imeli možnost pri vseh uradnih zadevah v Sloveniji uporabljati tolmača, bi se kljub temu želeli učiti slovensko? Zakaj?«

Vsi razen enega intervjuvanca so intervju opravili v slovenščini, kar je zelo jasen pokazatelj njihove motivacije za učenje slovenščine. Intervjuvanec Iran M30, ki je v času intervjuja v Sloveniji bival šele en mesec in pol, $\mathrm{v}$ času ponovitvenega intervjuja pa slabih 5 mesecev, je kljub temu izrazil zelo močno željo, da bi se naučil slovensko, saj bi se rad sporazumeval z okolico:

»Tu v Ljubljani ljudje znajo angleško, v majhnih mestih pa znajo samo slovensko. Z njimi ne morem govoriti angleško. Ključnega pomena je, da se naučim slovensko. ${ }^{10}$

Tudi drugi intervjuvanci so poudarjali pomembnost slovenščine, in sicer predvsem zato, ker jim ta po njihovem mnenju omogoča večjo samostojnost. Ukrajina Ž42 pravi: »Nočem biti odvisna.« Podobno tudi Afganistan M19 meni, da je slovenščina pomembna:

»Ker živim tukaj in se moram naučiti. Ne učim se samo zaradi uradnih opravkov, ampak tudi za vsakdanje življenje.«

Za Ukrajino M23, s katerim smo opravili ponovitveni intervju, pa znanje jezika države gostiteljice predstavlja še več, in sicer, kot pravi sam: »Bolj svoboden bi bil.» Najkompleksnejši odgovor na to vprašanje je podal Afganistan M22, ki v Sloveniji biva že 5 let. Znanje slovenščine se mu zdi pomembno, ker mu omogoča hitrejšo integracijo:

"Zato ker se ti odprejo vrata, ki ti omogočajo hitrejše napredovanje oz. integriranje v družbi, kjer živiš. In mislim, da je to tudi vljudno s strani enega tujca, da to naredi, zaradi tega, ker živi v tistem okolju oz. v tisti državi, in to pokaže neko spoštovanje, da se ti trudiš za njihov jezik."

Obenem je na ta način omogočeno, da se izognemo tolmaču, ki kot posrednik pogosto ne prenese tistega sporočila, ki ga govorec želi podati:

»To sem opazil večkrat, da prevajalci, večina teh prevajalcev ni zmožna dojeti tega, kar ti hočeš razumeti ... Ali ne znajo razumeti ali ne znajo, kaj jaz vem ... Ali ti ne moreš tako razložiti, kot si želiš, ane. Potem pač pride do pomanjkanja informacij, ko pride do tretje osebe.«

10 "Here in Ljubljana, people know English, but in small towns, people just know Slovene. I can't speak English with them. It's vital to learn Slovene.« 


\section{Sklep}

Pričujoča raziskava je poskušala odgovoriti na vprašanje, ali jezikovna podpora $\mathrm{v}$ obliki prevajanja in tolmačenja, ki jo država nudi nedavnim priseljencem, zmanjšuje motivacijo te populacije za učenje dominantnega jezika države. Raziskavo smo izvedli na skupini prosilcev za mednarodno zaščito, torej na skupini nedavnih priseljencev v Slovenijo, ki ji, na eni strani, država omogoča tolmaško in prevodno podporo v uradnih postopkih (in postopkih $\mathrm{v}$ zdravstvenem varstvu) ter ji obenem, na drugi strani, omogoča udeležbo na brezplačnih tečajih slovenskega jezika in kulture. Zanimalo nas je, ali tolmaška podpora dejansko zmanjšuje željo po učenju slovenščine.

Rezultati raziskave odnosa prosilcev za mednarodno zaščito $\mathrm{v}$ azilnem domu na Viču v Ljubljani do učenja slovenščine kažejo, da se migranti, ki jim je v azilnem postopku omogočena tolmaška podpora in so tako seznanjeni s takim načinom jezikovne podpore, kljub temu zavedajo pomembnosti znanja dominantnega jezika države gostiteljice. $\mathrm{V}$ nasprotju s predvidevanji zagovornikov enojezikovnosti $\mathrm{v}$ državnem okviru migranti v tolmaški in prevodni podpori ne vidijo najidealnejše in najbolj zaželjene jezikovne strategije. Nasprotno, mnogi izražajo nelagodje ob tem, da jim pri komunikaciji pomaga posrednik, ki mu pogosto ne zaupajo, da v resnici prenese vse, kar bi želeli povedati sogovorniku v tolmačenem sporazumevanju. Stalno podporo tolmačenja in prevajanja zavračajo tudi zato, ker jim onemogoča popolno samostojnost in neodvisnost ter zaželeni neposredni stik z okolico.

Ob tem je treba dodati, da se intervjuvanci zavedajo, da je tolmačenje in prevajanje kljub vsemu pomembno v visoko tveganih situacijah, kot so na primer sodni postopki, azilni postopek, bolnišnična oskrba in postopki centrov za socialno delo, kjer je natančnost izraza pomembna, lahko celo usodna, in sicer predvsem v prvih fazah bivanja v državi gostiteljici. Eden izmed intervjuvancev (Afganistan M22) tako opiše, kdaj je potreboval tolmače in prevajalce:

»Največ je bilo na začetku, ko nisem znal slovenskega jezika. Večinoma sem to rabil pri uradnih postopkih, kar se tiče intervjujev, kar se tiče drugih obveznosti. Tudi pri zdravstvenih storitvah, recimo pri zdravniku pa to, sem vedno rabil nekoga, ki zna razlagat to, kar sem hotel povedati.«

$\mathrm{V}$ teh visoko tveganih situacijah je kakovostna tolmaška in prevajalska podpora migrantom, ki so ravnokar prispeli $\mathrm{v}$ državo, morda celo bolj $\mathrm{v}$ interesu države gostiteljice, saj na ta način, kot kažejo raziskave (Lindholm, M. in dr., 2012; JohnBaptiste, A., Naglie, G., Tomlinson, G. in dr., 2004), zmanjša stroške za zdravstveno oskrbo in zagotovi pravičnost sodnih postopkov (Hertog, 2015). Zato toliko bolj preseneča, da nekatere države, kot je na primer Nemčija, razmišljajo o ukinitvi 
brezplačne tolmaške podpore nedavnim migrantom $\mathrm{v}$ zdravstvenem varstvu (Anthony, 2016).

Na osnovi raziskave lahko torej zaključimo, da je ustrezno izoblikovana jezikovna in prevodna politika eden izmed odločilnih dejavnikov, ki neposredno vpliva na procese inkluzije v ciljno družbo. Raziskava je pokazala, da je osnovne kompromise mogoče doseči, saj prevajalska in tolmaška podpora migrantov ne ovira pri učenju dominantnega jezika države gostiteljice, temveč predstavlja komplementarne korake do neodvisnosti priseljencev in njihove uspešne inkluzije v jezikovno in ekonomsko skupnost države gostiteljice.

\section{Literatura}

Anthony, T., Keine Dolmetscher für Flüchtlinge beim Arzt: Wenn der Arzt den Patienten nicht versteht..., Tagesschau.de, 6. julij 2016, www.tagesschau.de/inland/ integrationsgesetz-125.html [20. 7. 2016].

Beardmore, E., Sheffield Council blasted for spending $£ 700,000$ on translation, The Star, 18. februar 2015, http://www.thestar.co.uk/news/sheffield-council-blastedfor-spending-700-000-on-translation-1-7111386 [18. 7. 2016].

Beckford, M. in dr., How you pay $£ 100$ m a year to aid immigrants who can't speak English: Shock figures reveal huge sums spent on translators by police, councils and hospitals, The Mail on Sunday, 10. januar 2015, http://www.dailymail.co.uk/ news/article-2904814/Shock-figures-reveal-huge-sums-spent-translators-policecouncils-hospitals.html\#ixzz4EgEp7yFq [18. 7. 2016].

Easton, M., Cost in Translation, BBC NEWS, 12. december 2016, http://news.bbc. co.uk/go/pr/fr/-/2/hi/uk_news/6172805.stm [18. 7. 2016].

Ertl, A. in dr., Training (Medical) Interpreters-the Key to Good Practice. MedInt: A Joint European Training Perspective, v: The Journal of Specialised Translation 14, 2010, http://www.jostrans.org/issue14/art_ertl.php [18. 7. 2016].

Grin, F. in dr., Mobility and Inclusion in Multilingual Europe: A Position Paper on the MIME Project, 2014, http://www.mime-project.org/resources/MIMEPOSITION-PAPER-V4 [18. 7. 2016].

Hertog, E., Directive 2010/64/EU of the European Parliament and of the Council on the Right to Interpretation and Translation in Criminal Proceedings: transposition Strategies with Regard to Interpretation and Translation in Criminal Proceedings, v: MonTi 7, 2015, str. 73-100.

Iredale, T., $£ 140 \mathrm{~m}$ bill for public sector translation, BBC NEWS, 28. januar 2014, http:// www.bbc.com/news/uk-england-25933699 [18. 7. 2016]. 
Meylaerts, R., Translation policy, v: Handbook of Translation Studies 2 (ur. Gambier, Y., van Doorslaer, L.), Amsterdam, Philadelphia 2011a, str. 163-168.

Meylaerts, R., Translational justice in a multilingual world: an overview of translational regimes, v: Meta 56/4, 2011b, str. 743-757.

MIME, http://www.mime-project.org/, 2015 [18. 7. 2016].

O'Rourke, B. in dr., “Top-down” or "bottom-up”? Language policies in public service interpreting in the Republic of Ireland, Scotland and Spain, v: Interpreting and translating in public service settings (ur. de Pedro Ricoy, R. in dr.), Manchester 2009, str. 33-51.

Ozolins, U., Factors that Determine the Provision of Public Service Interpreting: Comparative Perspectives on Government Motivation and Language Service Implementation, v: The Journal of Specialised Translation 14, 2010, http://www. jostrans.org/issue14/art_ozolins.php [18. 7. 2016].

Pickles, E., Translation into foreign languages, 2013, https://www.gov.uk/government/ speeches/translation-into-foreign-languages [18. 7. 2016].

Pym, A., "Languages for integration or mobility?" Plenary speech at Translating Cultures: A Symposium, the UK Arts and Humanities Research Council, 2014, http://translating.hypotheses.org/415 [18. 7. 2016].

Schäffner, C., Behindert übersetzung die Integration?, v: "Meine Sprache grenzt mich ab...”. Transkulturalität und kulturelle übersetzung im Kontext von Migration (ur. Vorderobermeier, G., Wolf, M.), Dunaj 2008, str. 169-188.

Schäffner, C., Does Translation Hinder Integration?, v: Forum 7/1, 2009, str. 99-122.

Schuck, P. H., “Immigrants' Incorporation in the United States after 9/11: Two Steps Forward, One Step Back", v: Bringing Outsiders In: Transatlantic Perspectives on Immigrant Political Incorporation (ur. Hochschild, J., Mollenkopf, J.), London 2009, str. 158-175.

Vargas Urpi, M., State of the art in Community Interpreting Research: Mapping the Main Research Topics, v: Babel 58/1, 2012, str. 50-72.

Zakon o mednarodni zaščiti, Uradni list RS, št. 22/2016, 25. 3. 2016, https://www. uradni-list.si/1/content?id=125808 [20. 7. 2016]. 
Nike Kocijančič Pokorn, Iva Jevtič, Jaka Čibej

\section{"Nočem biti odvisna«: \\ Ali javne prevajalske in tolmaške storitve res negativno vplivajo na aktivno vključenost migrantov v državo gostiteljico?}

Ključne besede: prevajanje in tolmačenje za skupnost, prosilci za mednarodno zaščito, migracije, mobilnost, inkluzija, integracija, jezikovna politika, prevodni režim

Prispevek se sprašuje o upravičenosti določenih političnih ukrepov, ki odrekajo zagotavljanje prevajanja in tolmačenja migrantom, ter zagovarja nove pristope $\mathrm{k}$ jezikovni in prevodni politiki, in sicer prek raziskave, ki je bila zasnovana kot odziv na trditve, da prevajalske in tolmaške storitve ovirajo integracijo nedavnih priseljencev. Raziskava je bila izvedena na skupini prosilcev za mednarodno zaščito $\mathrm{v}$ azilnem domu v Ljubljani. Najprej smo zbrali podatke o jezikovnem ozadju vseh stanovalcev azilnega doma v avgustu 2014 (56 stanovalcev iz 19 različnih držav), nato pa sestavili reprezentativno skupino 18 prosilcev za mednarodno zaščito na podlagi njihovega maternega jezika in jih razdelili na dve skupini glede na čas bivanja v Sloveniji v času intervjuja (krajše ali daljše obdobje). Kvantitativne podatke o jezikovnih profilih smo zbrali z vprašalnikom, kvalitativne pa s pomočjo polstrukturiranih intervjujev, izvedenih v letu 2014, in dveh ponovitvenih intervjujev v letu 2015. Nato smo kvalitativno analizirali transkripcije vseh posnetih intervjujev, pri čemer smo se osredotočali na jezikovne in komunikacijske rešitve na različnih stopnjah migrantovega življenja v državi gostiteljici. Rezultati kažejo, da je osnovne kompromise mogoče doseči, saj so prevajalske in tolmaške storitve komplementarni koraki do neodvisnosti in kot take ne ovirajo učenja dominantnega oz. nacionalnega jezika države gostiteljice, temveč ga podpirajo. 
Nike Kocijančič Pokorn, Iva Jevtič, Jaka Čibej

\section{"I don't want to be dependent": Does Public-Service Translation and Interpreting Provision Impede the Inclusion of Migrants in the Host Country?}

Keywords: public service interpreting and translation, asylum seekers, migration, mobility, inclusion, integration, language policy, translation regime

By challenging some of the existing political claims regarding translation and interpreting provision to migrants, the article argues for new approaches in language policies related to translation and interpreting services. The research attempts to respond to the claims that translation and interpreting impedes integration of recent immigrants by conducting a quantitative and qualitative research among a group of asylum seekers settled in a detention centre in Ljubljana, Slovenia. First, we gathered data on the structure and language profiles of all the residents in the detention centre in August 2014 (56 residents from 19 different countries); then a representative group of 18 asylum seekers in terms of their first language was selected and put into 2 groups based on their length of stay in Slovenia at the time of their interview (shorter vs. longer periods). A questionnaire was used to gather quantitative data on the language profiles, while the qualitative data was obtained through semi-structured interviews in 2014 and two repeat interviews in 2015. A narrative analysis of the transcriptions of all recorded interviews was made, focusing on different languages and communication solutions in different stages of a migrant's life in the host country. The results show that basic trade-offs are possible: translation and interpreting are complementary steps to independence, which assist rather than impede acquisition of the dominant, i.e. national language, of the host country. 